\title{
An Investigation on the Share of Rural and Urban Households' Expenditure as A Basis to Determine Economic Policies for Iran
}

\section{Hamidreza Izadi}

\begin{abstract}
Many countries implement plans and programs whose purpose is low-income class protection and increase the purchasing power in order to eradicate poverty. The most common plan is the subsidies payment for consumption of deficits. Governments provide inexpensive goods and services and help to make price stability for necessities by applying policy in consumption sector. This research studies consumption expenditure shares in rural and urban households according to the importance of this issue and accordingly expenditure shares are rated and it is the basis of targeting subsidy policy. This article by use the MICROFIT program (ARDL method, 42 observations used for estimation from 1977 to 2019), tries to survey the short and long-term relationship, the dynamic relationship of short-term trend toward long-term equilibrium, diagnostic and structural break tests for the variables and the household costs function. According to the results of statistic tests, the model presented the best possible status of classic hypotheses and statistics and therefore confirm the relationship and co-integration between the variable of cost function and finally, structural stability is accepted. By comparing the urban household costs, according to the results we can say that the food is ranked among the goods with low rank, therefore, targeting the subsidies is less important than the rest of the cost. Also, the cost share of clothing goods is totally high for households and in urban households' expenditures, the cost share of these goods is higher than the rest, so these costs play an important role in targeting the subsidies and should be taken into consideration. By comparing the rural household costs, we can say, the contribution of educational, cultural and recreational services costs for rural households is high and thus the share of the allocated expenditures for such goods is higher than the rest. Therefore, these costs play an important role in targeting the subsidies and should be taken into consideration. Finally, targeting subsidy helps government to arrange subsidy rate of different goods correctly. and give the most to low income classes to boost social welfare. Result show that targeting subsidy in rural and urban is different because of different expenditures share in household budget, and the same economics policy for these two household types is not correct.
\end{abstract}

Keywords: Economic Policies; Urban Household; Rural Household; Subsidy; Targeting

JEL Classification: C13, D10, E20, H24, H71

\footnotetext{
* Hamidreza Izadi is assistant professor of Department of Economics at the Faculty of Management and Humanities, Chabahar Maritime University, Iran.Email: izadi@cmu.ac.ir
} 


\section{Introduction}

The subsidies are considered as important supportive tools of the governments, which are paid to support consumers, producers and exporters. Generally, subsides, as an economic policy, are the governmental supports which not only enable consumers to purchase goods and services by lower prices than the market prices, but also increase producers' income compared to the status without intervention (or decreased production costs). The subsidies are paid in order to achieve important goals, including:

1- Supporting the activities subject to the returns in an increasing scale (e.g. pubic goods)

2- Supporting the activities with positive external effects

3- Improving the income distribution and supporting the target groups (Paying subsidies for essential products).

However, it should be noted that subsidies payment merely does not guarantee higher social welfare and thus effectiveness of subsides on economy can be assured only when such supportive tools are used objectively. Accordingly, in present study, the experiences of Middle East and Northern Africa (MENA) countries regarding modification of subsidies payment methods- particularly in foodstuff area- were assessed by a review on historical trend of subsidies payment.

Generally, the goods can be divided into two categories in terms of subsidies payment and utilization of income groups:

1- The goods for which subsidies are paid by the government and are utilized by all income groups almost with a same amount for all groups or even sometimes contribution of high income groups is more. The higher usage of these commodities by a person or household, the higher contribution of subsidies will be assigned to them.

2- Goods that are not subject to subsidies and, despite this, lower income groups use them more. In the case of paying subsidies on these goods, given their higher share in the basket of poor households and low income earners than the higher ones, low-income groups in the community will benefit more from such subsidies.

Subsidies may be assigned for several reasons, such as lowering the price level (through increasing the buyers' real purchasing power) or maintaining the production process of a given commodity. However, subsidy payments may lead to undesirable resources allocation through distorting market prices and cost of production, although these disorders can also be compensated (through external effects). The subsidy is defined as follows: the amount of the difference in the cost price (real) of a good or service along with its adjusted price to support the target group, which is paid by an authority to not only support the target group but also to meet the authenticated expectations (Izadi et al., 2011). 


\section{Research history}

Mahmoodzadeh, Sadeghi and Heidari (2012), investigated the impacts of eliminating electricity subsidy during 1995-2007 using dynamic panel data model. Their findings showed that there was a negative and significant relationship between electricity energy intensity and its price and increased price index of other inputs which led to the replacement of the electricity. Also, using obtained dynamic functions the political plan of electricity price liberalization is implemented through 2010 to 2014 assuming the steady rise in nominal prices which after the liberation of electricity prices, energy intensity decreases so that the highest reduction has happened in the first year of liberalization, and in later years, the rate of decline in energy intensity has been reduced.

Manzoor, Shahmoradi and Haghighi (2010), investigated the impacts of increased energy carrier prices. Their study involved all of the goods of economy in 36 categories and all the economic sectors in 18 economic activities related to the energy. The results of their study indicated that increased price of energy carriers led to a decrease in households' welfare and the level of domestic production. Except for the upstream energy sector, other sectors faced with decreased activity level. Also, the demands of productive activities for energy as well as household's energy consumption would decrease.

Davoudi and Ashrafi (2009), in their studies on different countries of the world, show that each country employs a particular method or a combination of several methods for paying subsidies according to its specific circumstances. However, in the region of North Africa and the Middle East, programs are similar in terms of type of subsidized goods, targeting mechanisms and subsidies amount. In general, subsidies in these countries can be divided into two categories of subsidies for energy carriers and foodstuff, however, foodstuff subsidies are an important part of social protection programs.

In spite of using different mechanisms for allocation of food subsidies, improvement of their food security was their primary goal. Subsidies in this area include a wide variety of subsidies including general subsidies (Iran and Yemen), targeted systems (Tunisia), rationing systems (Egypt and Morocco), and alternative targeting programs (Algeria and Jordan). Generally, the key issue is that subsidy costs make a significant contribution to government spending in the countries that greatly affect the resources required (taxes) and the entire economy. Examining experiences of different countries shows that governments have used food subsidies against cash payments and in pursuit of subsidy goals. This was done despite the fact that the realization of these goals through the transfer of income has enjoyed less economic distortion. Jordan, however, is no exception to this general rule, as it has been successful in the cash flow transfer program.

In a study entitled "Designing a Comprehensive Subsidy Scheme", Manavi (2001) explored how to pay and allocate the subsidies efficiently. The results indicate that subsidies payment in the past years have been made publicly and untargetedly, which has led to the formation of irrational consumption patterns, in particular for essential 
commodities and energy carriers, and on the other hand, to higher benefit of high earners compared to lower ones.

Kashi et al., (2004) refer to this statement which is a goal of social and economic development programs of a country. In order to achieve this goal, annual considerable amounts are allocated to food subsidies in the state budget. So, it is worth considering the role of subsidy items in the consumption basket of households. This study is an attempt in this regard. In doing so, firstly, the estimated nutritional values of urban and rural households were estimated, then the contribution of subsidy items was calculated in terms of providing food values of households. Economists believe that interest rates (or bank charges) in the banking system of a country are less than necessary. Therefore, it is proposed to increase it in such a way that the inflation rate turns into a positive figure. Such an attitude, that only pays attention to the mobilization and equipping the financial resources through increased savings in the banking system, cannot be a proper solution for capital accumulation, while the accumulation is faced with inefficiency and excessive waste of resources. The problem is that with the policy of raising interest rates, the financial resources are more equipped, but in the investment phase, due to such reasons as weaknesses in management, lack of rules and regulations and high corruption, those resources are leaking and losing their effectiveness. Consequently, the average duration of investment in the Iranian economy (the average duration of each investment project from the beginning to the exploitation time) is even double that of the global standard, according to the official figures of the Iranian Management and Planning Organization.

By supporting private capital and directing monetary and financial resources to a system of exploiting resources through profit incentives and within the framework of capitalist standards, governments actually affect the economic growth and employment. These effects may be low or high, and depend on the state's optimal performance against private activities. However, the same governments, with their more or less intervention in the economy, are at the same time responsible for defending the private sector's activities, and their interference and involvement are applied to make the private sector productive (regardless of the exceptional and incorrect cases), which create imbalances that must be controlled by themselves as assigned. These imbalances include inflation, unemployment, technology, social expectations, investment risks and, most importantly, poverty and social discrimination.

The two main objectives of subsidies are to boost production in sectors that somehow need external motivation and their continued activity is beneficial for society and the economy. The second is to compensate the imbalances that have been arisen in the distribution of income in the process of capitalist economic life. In the former, subsidies are appeared as a contribution to production costs and thus a part of the manufacturing investment process and they should be taken into account in such new economic calculations. In the latter case, compensating for imbalances is to secure the purchasing power, prevent the destruction of poor lives and reduce discrimina- 
tion. These goals are both tools and outcomes of development. They are tools because they enhance the purchasing power and the domestic market, and the economy, like the Iranian economy, is and should be heavily reliant on this market. Also, they are outcomes because they cause poor households to some extent prevent or even upgrade labor productivity with partial compensation for deprivations.

\section{Methodology}

\section{The model variables}

Optimizing the subsidies, to be honest, will be very correct and acceptable. Subsidies should reject themselves in the long run through general development, rely on the necessary financial resources, be compatible with the type and degree of development, and ultimately be efficient, namely, they should cover more demanding and more effective groups (in terms of production) (by demographic and Earnings) well and not be available to high-income or ineffective individuals. In order to achieve such an appropriate strategy and optimize the structure of subsidies, it makes sense to examine the share of consumption expenditure at the expense of the entire household and to classify household expenses for the Subsidies Targeting Policy.

In the study of the household costs function, the total household expenses were used as a dependent variable and variables such as costs of food, drinking and tobacco, clothing and footwear, housing, fuel and lighting, home and office furniture, health and care, transportation and communications, educational, cultural and recreational services, other goods and services are used as explanatory variables. In our model, we divide the household into two urban and rural categories, and we estimate for the two models.

Logarithm for food and beverage costs of urban households (LEAC)

Logarithm for clothing costs of urban households (LWEC)

Logarithm for fuel, housing and lighting costs of urban households (LFUC)

Logarithm for transportation and communications costs of urban households (LTRC)

Logarithm for educational, cultural and recreational costs of urban households (LDIC)

Logarithm for costs of the family as a whole (LFTC)

Logarithm for food and beverage costs of rural households (LEAV)

Logarithm for clothing costs of rural households (LWEV)

Logarithm for fuel, lighting and housing costs of rural households (LFUV)

Logarithm for transportation and communications costs of rural households (LTRV) Logarithm for educational, cultural and recreational costs of rural households (LDIV)

According to Augmented Dickey-Fuller (ADF) unit root test to assess stationarity of the variables, the results are presented in Table (1) along with critical values (at the level of 5\%) about variables of present paper. 
Table 1: Augmented Dickey-Fuller (ADF) unit root tests

\begin{tabular}{|c|c|c|c|}
\hline Variable & ADF TEST & Variable & ADF TEST \\
\hline LEAC & $I(1)$ & LEAV & $I(1)$ \\
\hline LWEC & $I(1)$ & LWEV & $I(1)$ \\
\hline LFUC & $I(1)$ & LFUV & $I(1)$ \\
\hline LTRC & $I(1)$ & LTRV & $I(1)$ \\
\hline LDIC & $I(1)$ & LDIV & $I(1)$ \\
\hline LFTC & $I(0)$ & & \\
\hline
\end{tabular}

Source: Research calculations

\section{The model estimation}

In this paper, considering the existing variables, two proposed models are considered, which we will use to estimate the model. The table for estimating the urban household costs function is as follows:

Table 2: Estimation of the urban household costs function

\begin{tabular}{|c|c|c|c|}
\hline Variable & Coefficient & Standard Deviation & t-test \\
\hline DLEAC & 0.0921 & 0.0764 & $1.20(0.23)$ \\
\hline DLWEC & 0.265 & 0.0537 & $4.94(0.00)$ \\
\hline DLFUC & 0.156 & 0.0584 & $2.67(0.01)$ \\
\hline DLTRC & 0.153 & 0.0428 & $3.57(0.00)$ \\
\hline DLDIC & -0.0433 & 0.0304 & $-1.42(0.16)$ \\
\hline C & 0.0072 & 0.0087 & $0.82(0.41)$ \\
\hline
\end{tabular}

Source: Research calculations, Data's are extracted from the Reports of the Central Bank of Iran (1977 to 2019), database: https://www.cbi.ir.

The estimation results indicate that the cost of foods, beverages and tobacco in urban households has a direct and positive impact on the total household costs. The estimated coefficient for these costs (0.092) is positive and insignificant. In other words, a one percent increase in food and beverage costs increases the total household costs as much as $0.90 \%$ and thus has no significant importance.

The cost of urban household clothing has a direct and positive impact on the total household cost. The estimated coefficient for these costs is 0.265 with a positive sign. In other words, a one percent increase in cost of clothing and footwear will increase the total household costs as much as $0.265 \%$.

The cost of urban household fuel and lighting has a direct and positive impact on the total household cost. The estimated coefficient for these costs is 0.156 with a positive sign. In other words, a one percent increase in cost of the household fuel and lighting will increase the total household costs as much as $0.156 \%$.

The cost of urban household transportation and communications has a direct and positive impact on the total household cost. The estimated coefficient for these costs 
is 0.153 with a positive sign. In other words, a one percent increase in cost of the household transportation and communications will increase the total household costs as much as $0.156 \%$.

The cost of urban educational, cultural and recreational services has an inverse and negative impact on the total household cost. The estimated coefficient for these costs is 0.042 with a negative sign. In other words, a one percent increase in cost of the household educational, cultural and recreational services will decrease the total household costs as much as $0.042 \%$. As a matter of fact, the negative relationship suggests that the urban household recognizes the cost of educational, cultural and recreational services as a factor to reduce its total costs. It can be argued that the suitability of these costs is high and the household, in terms of obtaining the satisfaction of these costs, will be waived for this cost and do not look at it as a cost. In fact, the suitability at this cost is more than the cost itself.

By comparing the above costs, these items are ranked from 1 to 4, respectively: clothing goods, energy, transportation, and foods. Considering the second rank of energy costs and its coefficient for correcting the consumption patterns of a country, optimal energy consumption management and fair distribution of subsidies, targeting the subsidies seems to be necessary. On the other hand, the third category of transportation costs reflects the significant share of this sector in the household costs and, nevertheless, the gradual increase of these costs in order to equate its subsidy leads to pollution control and consumption reduction. According to the results, the food is ranked among the goods with the rank 4, therefore, targeting the subsidies is less important than the rest of the cost. The cost share of clothing goods is totally high for households and in urban households' expenditures, the cost share of these goods is higher than the rest, so these costs play an important role in targeting the subsidies and should be taken into consideration.

Table 3: Diagnostic tests and statistics

\begin{tabular}{|c|c|c|c|}
\hline Serial Correlation & Functional Form & Normality & Heteroscedasticity \\
\hline $0.05(0.941)$ & $2.392(0.122)$ & $2.220(0.329)$ & $1.347(0.505)$ \\
\hline
\end{tabular}

Source: Research calculations, Data's are extracted from the Reports of the Central Bank of Iran (1977 to 2019), database: https://www.cbi.ir.

According to the results of diagnostic tests, the model can be argued to have the best possible status and no problem in terms of classic hypotheses and structural break statistics.

In order to investigate the null hypothesis, which indicates lack of coincidence or long-term relationship, we conducted the co-integration test and studied the dynamic relationship of short-term trend toward long-term equilibrium. In order to investigate the long-term relationship and confirm the non-falsity of this relationship with regard to the optimal interruption or the maximum Schwartz-Bayesian Statistics, the 
co-integration test was carried out. Since the absolute value of the obtained statistics (5.163) is larger than the critical value (3.86), a long-term relationship is confirmed at a significance level of $95 \%$.

Plot 1: Cumulative Sum of Recursive Residuals (CUSUM) and Cumulative Sum of squares of Recursive Residuals (CUSUMSQ)

\section{Plot of Cumulative Sum of Recursive Residuals}

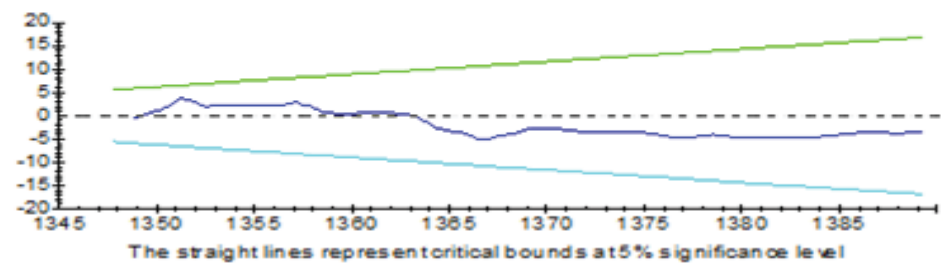

\section{Plot of Cumilative Sum of Squares} of Recursive Residuals

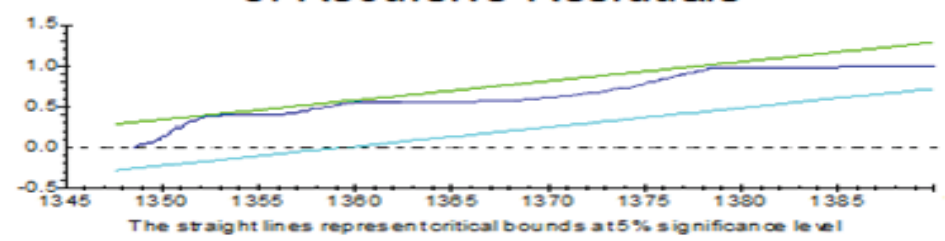

According to the plot of Cumulative Sum of Recursive Residuals (CUSUM) and Cumulative Sum of Squares of Recursive Residuals (CUSMUSQ), the null hypothesis regarding presence of structural stability is accepted and its absence is rejected, actually confirming existence of structural stability. On the other hand, given this stability, it can be argued that by applying monetary and fiscal policies, the probability of reaching the goal of these policies is very high.The results for estimating the rural household costs function are shown in Table (4).

Table 4: Estimation of the rural household costs function:

\begin{tabular}{|c|c|c|c|}
\hline Variable & Coefficient & Standard deviation & t-test \\
\hline DLEAV & 0.0263 & 0.0231 & $1.02(0.41)$ \\
\hline DLWEV & 0.2863 & 0.0511 & $1.20(0.23)$ \\
\hline DLFUV & 0.265 & 0.0537 & $5.59(0.00)$ \\
\hline DLDIV & 0.2991 & 0.0344 & $8.67(0.00)$ \\
\hline DLTRV & 0.230 & 0.0532 & $4.33(0.00)$ \\
\hline C & 7.651 & 0.3044 & $25.13(0.00)$ \\
\hline
\end{tabular}

Source: Research calculations, Data's are extracted from the Reports of the Central Bank of Iran (1977 to 2019), database: https://www.cbi.ir. 
It can be argued that since the rural households are mostly both food consumers and producers, the household's food costs were insignificant in this model. The Estimation results indicate that the clothing cost of rural households has a direct and significant effect on the total household cost. The estimated coefficient for these costs is 0.2886 with a positive sign. In other words, one percent increase in this cost will increase the amount of total rural household cost as much as $0.286 \%$. Given the insignificance, this factor indicates that importance of this goods is not high for the rural household.

In addition, fuel and lighting cost of rural households has a direct and significant effect on the total household cost. The estimated coefficient for these costs is 0.265 with a positive sign. In other words, one percent increase in fuel and lighting cost will increase the amount of total rural household cost as much as $0.265 \%$.

Accordingly, transportation and communication cost of rural households has a direct and significant effect on the total household cost. The estimated coefficient for these costs is 0.230 with a positive sign. In other words, one percent increase in transportation and communication costs will increase the amount of total rural household cost as much as $0.265 \%$.

Also, educational, cultural and recreational services cost of rural households has a direct and significant effect on the total household cost. The estimated coefficient for these costs is 0.299 with a positive sign. In other words, one percent increase in educational, cultural and recreational services costs will increase the amount of total rural household cost as much as $0.299 \%$.

By comparing the above costs, these items are ranked from 1 to 4, respectively: educational, cultural and recreational services, clothing goods, energy, and transportation. Considering the third rank of energy costs and its coefficient for correcting the consumption patterns of a country, optimal energy consumption management and fair distribution of subsidies, targeting the subsidies seems to be necessary. Besides, the fourth category of transportation costs reflects the significant share of this sector in the rural household costs. The contribution of educational, cultural and recreational services costs for rural households is high and thus the share of the allocated expenditures for such goods is higher than the rest. Therefore, these costs play an important role in targeting the subsidies and should be taken into consideration.

Table 5: Diagnostic tests and statistics

\begin{tabular}{|c|c|c|c|}
\hline Serial Correlation & Functional Form & Normality & Heteroscedasticity \\
\hline $2.669(0.102)$ & $0.117(0.7327)$ & $4.817(0.090)$ & $2.804(0.094)$ \\
\hline
\end{tabular}

Source: Research calculations, Data's are extracted from the Reports of the Central Bank of Iran (1977 to 2019), database: https://www.cbi.ir. 
According to the results of diagnostic tests, the model can be argued to have the best possible status and has no problem in terms of classic hypotheses and structural break statistics.

In order to investigate the null hypothesis, which indicates lack of coincidence or long-term relationship, we conducted the co-integration test and studied the dynamic relationship of short-term trend toward long-term equilibrium. In order to investigate the long-term relationship and confirm the non-falsity of this relationship with regard to the optimal interruption or the maximum Schwartz-Bayesian Statistics, the co-integration test was carried out. Since the absolute value of the obtained statistics (4.782) is larger than the critical value (4.040), a long-term relationship is confirmed at a significance level of $95 \%$.

Plot 2: Cumulative Sum of Recursive Residuals (CUSUM) and Cumulative Sum of Squares of Recursive Residuals (CUSUMSQ)

Plot of Cumulative Sum of Recursive Residuals

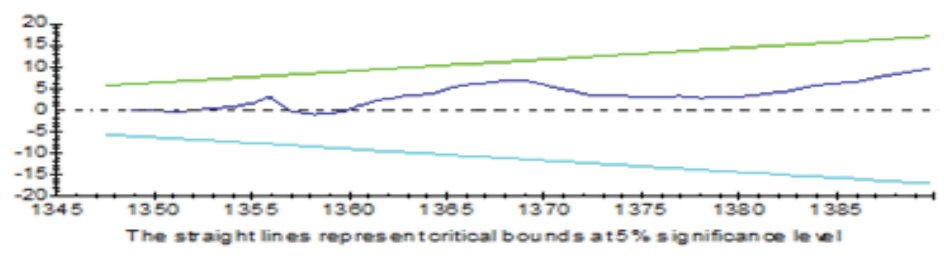

Plot of Cumulative Sum of Squares of Recursive Residuals

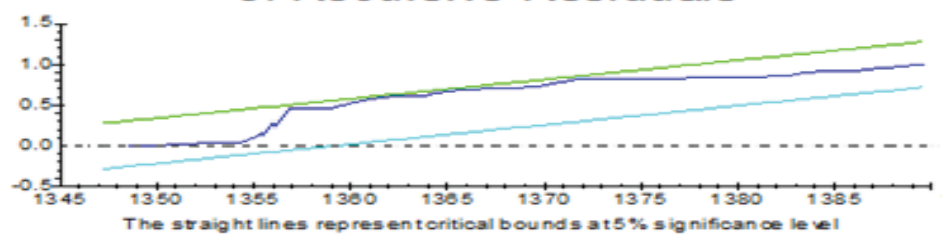

According to the plot of Cumulative Sum of Recursive Residuals (CUSUM) and Cumulative Sum of Squares of Recursive Residuals (CUSMUSQ), the null hypothesis regarding presence of structural stability is accepted and its absence is rejected, actually confirming existence of structural stability. On the other hand, given this stability, it can be argued that by applying monetary and fiscal policies, the probability of reaching the goal of these policies with the least policy-making interval is very high. 


\section{Conclusion and Suggestions}

Regarding the stability of the functions and the existence of long-term relationships for the subsidies targeting, there is a high probability of reaching the goals of these policies and reaching the target points with the least policy interruption, so choosing the accurate policy is very important.

An overview of the costs of Urban Household can be said that the costs are ranked respectively: clothing goods, energy, transportation, and foods. Considering the second rank of energy costs and its coefficient for correcting the consumption patterns of a country, optimal energy consumption management and fair distribution of subsidies, targeting the subsidies seems to be necessary. On the other hand, the third category of transportation costs reflects the significant share of this sector in the household costs and, nevertheless, the gradual increase of these costs in order to equate its subsidy leads to pollution control and consumption reduction. According to the results, the food is ranked among the goods with the rank 4, therefore, targeting the subsidies is less important than the rest of the cost. The cost share of clothing goods is totally high for households and in urban households' expenditures, the cost share of these goods is higher than the rest, so these costs play an important role in targeting the subsidies and should be taken into consideration.

An overview of the costs of Rural Household can be said that the costs are ranked respectively: educational, cultural and recreational services, clothing goods, energy, and transportation. Considering the third rank of energy costs and its coefficient for correcting the consumption patterns of a country, optimal energy consumption management and fair distribution of subsidies, targeting the subsidies seems to be necessary. Besides, the fourth category of transportation costs reflects the significant share of this sector in the rural household costs. The contribution of educational, cultural and recreational services costs for rural households is high and thus the share of the allocated expenditures for such goods is higher than the rest. Therefore, these costs play an important role in targeting the subsidies and should be taken into consideration.

Subsidies are considered as one of the most important economic instruments of the government in making supportive policies for vulnerable consumer groups. Targeting the subsidies is an assignment of the government, for which some actions have been taken since the second development plan, and even some rules have been developed accordingly. Targeting the subsidies based on cash payment given that the power of choosing and empowering the household can be one of the proper ways of paying subsidies and if properly implemented, vulnerable households will benefit most from it.

By comparing the rankings of the share of urban and rural households in paying effective subsidies to the social strata and looking at the ranking of the share of costs for urban and rural households, the cost of energy and transportation can 
be concluded to be appropriate for targeting the subsidies, that is, applying any policy on this variable has almost the same effect on urban and rural households budget. However, there is a difference in the share of these costs between the urban and rural households, but, this difference will be ignored with the same policy of targeting subsidies for both households in the country. On the other hand, it should be noted that the share of these two expenditures in rural households is higher than those of the urban households, and therefore the rural household needs more support in this regard and applying the same policies for both household types is not correct.

According to the results, it can be seen that the cost of food goods is in the first row of the urban households' costs, but in the ranking of rural household goods, the mentioned cost is not in the ranking of household goods since such households do production of foodstuff themselves, so the same targeting of subsidies for these costs among such two types of households is not correct. It should be noted that household expenditures (budget) and the share of the cost of these goods vary for urban and rural households.

The subsidies payment to compensate the inappropriate effects of asset development and distribution strategies is vital and important, but the co-operation of all the components of the government and the people to advance the plan, the accurate identification of vulnerable households and the share of costs from the total household cost, providing explanatory and briefing programs for recognition of the basics and determination pricing of valuation items, the review of redistribution, and compensation for losses suffered by households are crucial issues that government and policymakers need to consider and pay more attention in their policies.

Finally, by taking a glance on the share of costs in urban and rural households and given the greater share of rural household costs, the government should increase the share of rural households from subsidies and pay more to them by changing the contribution of household subsidies, or by applying the same payment policy, they would give the essential consumer goods to the rural households in the villages to compensate such a difference.

\section{REFERENCES}

Babaei, N., Dini, A., Raeesedana, F., Rafiei, H. \& Gharavinakhjavani, A. (2001). Review and Criticism of the Report of the Purposeful Subsidies System in Iran. Social Welfare Quarterly, 1(2), 59-74.

Davoudi, A. \& Ashrafi, Y. (2009). A Review on the experience of countries in targeting subsidies (Emphasizing food subsidies reform in the Middle East and North Africa). Journal of Economic Issues and Policies Review, 9(101), 111-129.

Iranian Organization for Management and Planning, (All years), Subsidies Purposeful System, Tehran, Iranian Organization for Management and Planning. 
Izadi, H.R., Abazari, E. \& Sargolzaei, F. (2011). Review, comparison and targeting of subsidies in Iranian consumption expenditures. National Conference on Economic Jihad and targeting the subsidies, Payame Noor University, Qom province, 24-39.

Kashi, K. \& Heidari, K. (2004). Evaluation of the role of food subsidy items in the consumer basket of urban and rural households. Quarterly Journal of Commercial Research, 32, 41-54.

Maanavi, M. (2001). Designing a Comprehensive Subsidies Payment Scheme. Economic Deputy Magazine of Iranian Ministry of Economic and Finance Affairs, 5(19), 145-170.

Mahmoodzadeh, M., Sadeghi, S., \& Heidari, F. (2012). The impact of eliminating electricity subsidy on energy intensity. Quarterly Journal of Planning and Budget, 4, 113-127.

Manzoor, D., Shahmoradi, A., \& Haghighi, I. (2010). Evaluating the effects of eliminating energy apparent and hidden subsidies in Iran using a computable general equilibrium model based on adjusted micro data matrix. Quarterly Journal of Energy Economics Studies, 26, 21-54. 